\title{
LEITURA E CRÍTICA DO CONHECIMENTO NA CONTEMPORANEIDADE
}

\author{
Paulo Sérgio Nolasco dos Santos*
}

\begin{abstract}
: linked to the intellectual's role, reading is not only reflection of knowledge power but it is also a remarkable trace of a critical activity, based on the knowledge revision and the definition of these same terms - knowledge, criticism, wisdom. Under the perspective of comparative literature and knowledge production, this article aims at considering the reading nature as a form of knowledge appropriation, to which is supposed within its own exercise and execution currently, the mission of distance and "articulatory" (re)placement from knowledge itself; remodeling it throughout its transformations and through the various nets that comprehend it, particularly when remodeled by the "contemporary view".
\end{abstract}

Keywords: literary reading, knowledge, contemporary

\section{À GUISA DE INTRODUÇ̃̃O}

\begin{abstract}
Se ao menos hoje em dia as pessoas tivessem esse tipo de humor, esse tipo de dignidade, pensou Clarissa, pois lembrava-se das passagens principais; dos finais de sentenças; dos personagens - falava-se sobre eles como se fossem de carne e osso. Para encontrar as coisas elevadas era preciso voltar ao passado, ela refletiu. Do contágio da lenta mácula do mundo... Não mais temas o calor do sol....* E mais não pode lamentar, não pode lamentar, repetiu, o olhar perdendo-se na janela; pois isso recorria-lhe à lembrança; a prova da grande poesia; os modernos jamais chegaram a escrever algo de interesse sobre a morte, pensou; e volveu-se ${ }^{1}$ (WOOLF, 1984, p. 186-187).
\end{abstract}

A epígrafe, extraída ao que se tornaria o célebre conto "Mrs. Dalloway na Bond Street", e matriz do romance Mrs. Dalloway, a obra-prima da escritora britânica Virginia Woolf recentemente reescrito na narrativa pós-moderna As horas, de Michael Cunningham, projetado no cinema com título homônimo - , não só convida provocativamente à uma valoração da leitura como conhecimento, perspicácia em deslindar a interdiscursividade, em uma prosa poética plena "de exatidão sábia, de alusões cultas e flutuações ágeis", como caracterizou o crítico e historiador Miklós Szabolcsi (1990, p. 97), mas sobretudo interessa, nessa provocação, sublinhar o processo ou poder de ressignificação de textualidades diferentes também em contextos diferentes, de forma a acompanhar o ato intelectivo e cognitivo do sujeito-leitor em

\footnotetext{
* Professor da Universidade Federal de Grande Dourados (UFGD).

1 "Mrs. Dalloway na Bond Street" foi originariamente escrito como primeiro capítulo do romance Mrs. Dalloway. O asterisco, na epígrafe, remete para a nota do tradutor em rodapé: "não mais temas o calor do sol"; Fear no more the heat o'the Sun. Réquiem de Cymbeline, de Shakespeare; Song, ato IV, cena II. Na realidade, trata-se da apropriação direta, ininterrupta, de dois versos, "Do contágio da lenta mácula do mundo... Não mais temas o calor do sol..." [sic] dos poetas Shelley e Shakespeare, respectivamente, evidenciando uma intertextualidade ao nível da simples alusão ou reminiscência, e que no nível do enunciado visa à interpenetração ativa de passado e presente no fluxo da consciência. A citação dos dois versos não só remete ao paradigma da "leitura" da tradição literária e cultural, da erudição da classe social à que os Dalloways pertenciam, por um lado, mas também, por outro, para a vida mundana, não-letrada, que a Senhora Dalloway observava enquanto caminhava na Bond Street.
} 
uma moldura de leitura traduzida pelo viés do sujeito contemporâneo. Aceitar esse convite provocativo e em demanda pela epígrafe woolfiana representará o (re)conhecimento de que o sujeito da escrita, já à época da escritora, portanto no auge do modernismo, mostrava-se descentrado tematizando, por assim dizer, um modo de olhar que ora fixava-se no passado ora no presente/futuro de sua escrita. Seja como tema literário e de livros propriamente dito, seja como gesto e atitude contumaz de escritores e intelectuais, em diversas épocas, a leitura como propriedade tradutora e de poderosa assunção do conhecimento, mais do que "elogios" encomiásticos, tornou-se um topos com referência e domínio público em nossa história recente, ao menos no ocidente. Dessa perspectiva, relacionar o ato de ler como derivativo da atividade intelectual, em contiguidade ao reconhecimento do lugar e papel do intelectual em nossa civilização, representa também a matriz e componente etimológico da explicação de ambos os agentes, ou seja, o sujeito que lê e, consequentemente, o sujeito/agente da intelectualidade. Isso significa que a presença do Outro, a alteridade, já reside na etimologia da própria palavra intelectual, conforme explica Maria Zilda Cury:

Do latim intellectualis, de que a palavra intelectual deriva, conservouse o sentido de "relativo à inteligência". Decompondo-se a palavra temos: intus, para dentro e lectus, particípio passado de legere (ler). Ler (para) dentro das coisas, para seu interior. Mas, o sentido etimológico do verbo legere "postula certa intensificação do fato social", na medida em que aponta para uma dimensão de exterioridade. Ler, pois, pressupõe um movimento para o exterior, para comunicar-se com os outros, fazendo uma leitura do mundo, o que dota a palavra intelectual dos dois movimentos: para dentro de si e para fora de si. Alargando o sentido ainda a partir da etimologia da palavra, salienta-se a condição intermediária do intelectual, sua função mediadora (CURY, 2008, p. 13).

Como se vê, a produção de conhecimento, ou de sentidos, estabelece estreitas relações mobilizando afinidades especiais tanto no ato de leitura, que nunca é puro deciframento de sinais, quanto na vontade e desejo mobilizados na direção da exploração e conhecimento, constitutivos e resultantes do que foi elevado à condição de um saber posto em articulação. Daí advém não apenas um modo de ler, de saber ler, como também e fundamentalmente um modo/poder de articular intelectivamente os objetos de conhecimento, e, assim, como observa Reinaldo Marques, caberia ao investigador "criar novos objetos de conhecimento. Isso supõe que os sujeitos do conhecimento sejam desinstalados de seus territórios e se disponham a atravessar suas fronteiras, adotando uma mobilidade que os habilita ao diálogo com outros sujeitos e seus referenciais teóricos" (MARQUES, 1999, p. 63).

Neste artigo propomos analisar o lugar (ou não-lugar) da literatura sob o foco da literatura e conhecimento. Tomando como base a questão da leitura da literatura, certa ontologia do sujeito do conhecimento perspectivado pela contemporaneidade e enfatizando o conhecimento como poder obtido sob premissas articuladoras de saberes e/ou produção de sentidos - leituras - , verificaremos como tais "leituras" não só influem em uma redefinição valorativa do conhecimento, no seu ressurgimento mas, também, o próprio projeto e a intenção do escritor ou intelectual confirmariam, ainda hoje, sua validade entre o pensar contemporâneo e o esgarçado tecido da vida sociocultural e política, na atualidade.

\section{LEITURA E CONHECIMENTO}

Reiniciamos, para o nosso propósito, lembrando três aspectos derivativos da palavra intellectualis que, na história das ideias e da civilização, teceram convergências decisivas na construção da prática de leitura como conhecimento: a primeira se refere à leitura, grosso modo, 
e é ainda Virginia Woolf o modelo de escritor/intelectual cuja fortuna crítica remarcará de forma indelével "seu extraordinário amor e defesa da leitura" (BLOOM, 1994, p. 414); a segunda refere-se ao amplo topos das viagens, o intelectual viajante, que durante todo o século XIX fizera das voltas ao mundo um itinerário obrigatório e vasto palco de exploração, e, como resultante dessas duas condições, a sedimentação do projeto moderno e humanista do conhecimento como confluência e substantivação de redes de concatenação dos saberes, o que vai nos interessar de modo nuclear na argumentação sobre a articulação do conhecimento na contemporaneidade.

Harold Bloom, em $O$ cânone ocidental, com o capítulo intitulado "Orlando de Virginia Woolf: feminismo como amor à leitura", destacou a escritora pelo seu "extraordinário amor e defesa da leitura", enfatizando que: "talvez tenha havido outros escritores em nosso século que amassem tanto a leitura quanto Virginia Woolf, mas ninguém desde Hazlit e Emerson expressou essa paixão de modo tão memorável e proveitoso quanto ela" (BLOMM, 1994, p. 415). Com efeito, ao compará-la com Freud como modelos de esplendor persuasivo, Bloom faz ressoar o poder inalienável de uma literatura que não se deixaria atar a modelos de interpretação teóricopolítica e crítica cultural, sem risco de expropriação e leviandade, assim abalizando seu julgamento - "não me lembro de outro romancista forte que centre tudo em seu forte amor à leitura como faz Virginia", em uma comparação que a aproxima do empreendimento analíticointerpretativo de Freud:

Talvez só Freud, em nosso século, rivalize com Virginia Woolf como estilista de prosa tendenciosa. A Room of One's Own [Um teto todo seu] tem uma intenção sobre seu leitor, e o mesmo acontece com $A$ civilização e seus descontentes, mas nenhuma consciência dessa intenção salvará o leitor de ser convencido quando passa pela polêmica magnificência de Freud e de Virginia Woolf. [...]. Freud antecipa nossas objeções e pelo menos parece responder a elas, enquanto Virginia insinua fortemente que nossa insatisfação com sua urgência se baseia na imperceptividade (BLOOM, 1994, p. 418).

Ao contrapor Orlando, famoso romance de Virginia, com um dos memoráveis ensaios críticos da escritora, "Como se deve ler um livro?", Bloom enaltece o vigor deste ensaio woolfiano, extraindo a seguinte passagem que prefiro citar na tradução d'O leitor comum, onde fui encontrá-la no ensaio referido, no final do livro:

Até quem lê para realizar um objetivo, não é de qualquer modo desejável? Não há certas atividades que praticamos porque são boas em si mesmas, e alguns prazeres que são conclusivos? E o que há entre tudo isso? Eu, pelo menos, algumas vezes tenho sonhado que quando raiar o Dia do Juízo Final e os grandes vencedores e advogados e estadistas chegarem para receber seus prêmios - suas coroações, seus lauréis, seus nomes indelevelmente gravados em mármore imperial - o Onipotente se virará para Pedro e dirá, não sem uma dose de inveja quando Ele nos vir chegando com nossos livros debaixo dos braços: "olhem, estes não precisam de troféus. Nada temos para lhes oferecer aqui. Eles amaram ler" (WOOLF, 2007, p. $135)$.

Com efeito, temos aí bastantes argumentos em prol da literatura nas suas contrafaces de "escrita" e de "leitura". Provocadora de persuasão, eloquência e poder, pode-se pensar a leitura de ficção como um exercício em transição, na medida em que o espaço delimitado pela folha de papel não consegue aprisionar a escrita, metáfora persuasiva, nem a leitura. Transição que é lugar fronteiriço da linguagem criadora, metafórica e poética, onde as palavras "andam à 
procura de seu sentido e nisso consiste o seu sentido" (PAZ, 1988, p. 121), ao lembrar que a literatura emite sentidos e depois corre atrás deles: "ao escrever, caminho para o sentido; ao ler o que escrevo, apago, dissolvo o caminho. Cada tentativa termina no mesmo: dissolução do texto na leitura, expulsão do sentido pela escritura" (PAZ, 1988, p. 121). Imaginemos Mrs. Woolf, mas sobretudo imaginemos a narradora Dalloway, protagonista de Mrs. Dalloway: qualquer tema se transformava em um conjunto de impressões que reunia ideias e opiniões antagônicas, sentimentos ora convergentes e divergentes, ora díspares e confluentes. Já não há mais tema, nem assunto, dos quais se possa ir procurando o fio condutor. Sua prosa de ficção não tem argumento no sentido narrativo da palavra. Há apenas uma consciência a elaborar uma prosa que não se pode ler em voz alta, teia coletora de insinuações que vão além, para um lugar ao qual os nomes jamais poderão ir. Em uma palavra: uma prosa endereçada aos sentimentos não expressos, que fere os seres e as coisas. A protagonista de Mrs. Dalloway busca a encenação estilizada das pulsões de uma consciência em choque com o mundo da percepção. Tentar delinear os movimentos da escrita em Mrs. Dalloway é, sem dúvida, sentir a impressão de encontrar-se achado/perdido por entre as malhas de uma escritura que corresponde ao vai e vem das ondas que vão passando indefinidamente pela consciência da narradora.

Tem razão o teórico da ficção ao dizer que o leitor de ficção é também um artista; que o seu esforço prolongador da recriação da forma da ficção compete com o do romancista. Daí a permanência de uma situação paradoxal (e vital, diríamos) que se mantém como tensão natural do leitor (o leitor crítico) que também é um romancista. O que permanece em nossas mãos após acabada a leitura de obras assim? É tudo e nada ao mesmo tempo: a obra fechada, nunca finda em sua leitura, uma vez que a profunda alegria, o êxtase secreto, ou um mal-estar de não nos sentirmos dentro do tempo é o que permanece. Em Mrs. Dalloway, a escritura é reflexo de um narrador que se desfaz em uma "ode ao Tempo". Ao compor sua ode ao Tempo, a narradora percebe que tudo se desvanece em pó, e que tudo é fabricado, "como se fabrica a melhor parte da vida", diz ela. Qual o sentido da festa de Mrs. Dalloway? Essa pergunta fica em suspenso nas consciências da própria Dalloway e de Peter Walsh, e acossa a consciência do leitor até o final da leitura. O sentido das recepções de Dalloway parecia a Peter Walsh ser uma "oferenda", também a narradora parece concordar: "e isso era uma oferenda; combinar, criar; mas oferenda a que?" O leitor não saberá a quem atribuir o sentido dessa oferenda, pois tudo em Dalloway provém de um dom criativo que rivaliza com o imediatamente útil e necessário; ela diz tratar-se de "uma oferenda pela própria oferenda, talvez". Assim, a oferenda ressurge resplendente em significações, simbolização de outra ordem, de uma nova natureza defendida para as coisas, ou de um olhar que possa esquecer o caráter transitório do dia-a-dia, para se encontrar na busca de um sentido mais pleno e menos transitório.

Texto-fragmento, inacabado, aberto e em movimento, "Mrs. Dalloway na Bond Street" atualiza uma atividade de reptação em relação a Mrs. Dalloway. Não só por sua posição de anterioridade, texto "escriptível", revelando uma feição "ensaística", que vai informar (formatar) a prosa de Mrs. Dalloway, adiantando-se, em procedimentos- técnicasinstrumentalização, às operações das linguagens e tecnologias contemporâneas, das quais os recursos estilísticos utilizados em um e em outro texto confirmam a presença de um narrador detentor na sua perspectiva da constituição própria de um critério de leitura. Se ninguém pensa em minimizar o efeito da linguagem sobre o pensamento, no entanto, há atividades muito elaboradas que, para se realizarem, não implicam a linguagem (LHERMITTE, 1985, p. 91). Parece pertinente observar que em arte, com a literatura e a pintura em relevo, o universo do discurso suscita inúmeros comentários, mas sua natureza intrínseca é pouco verbalizável. Seria preciso lembrar as inúmeras produções literárias? Fiquemos com dois exemplos que nos interessam: o afloramento lento e difícil da vivência de Marcel Proust, nos minúsculos fragmentos que desnaturam o seu texto, como no trecho antológico da madeleine tornando prenhe de vida a Combray proustiana, e a própria Virginia Woolf que, espreitando a vida através das cortinas ${ }^{2}$, estigmatiza o seu texto, traído pela terrível atividade da imaginação, o pior

\footnotetext{
${ }^{2}$ Refere-se aqui à figura da “cortina” como imagem recorrente nas projeções do sujeito woolfiano.
} 
dos tormentos - , observa ela: "as experiências da vida são incomunicáveis e é essa a causa de toda a desolação humana". Dessa forma, essas obras põem em tela uma complexidade cada vez maior do universo imaginário pela literatura, instigando uma crítica paralela atuante e questionadora, que visa a fazer da literatura uma experiência de combate e concorrência, logo, uma experiência verdadeiramente criadora. Com isso, a escrita e a leitura tornam-se concorrentes no âmbito do modernismo que as configura, como queria o nosso Machado de Assis, que, no capítulo trinta de Quincas Borba, se coloca na pele do leitor e faz um comentário revelador: "arrenego de um autor que me diz tudo, que me não deixa colaborar no livro, com a minha própria imaginação", ou, "a melhor página não é só a que se relê, é também a que a gente completa de si para si". No gesto de revolver em profundidade a vida da consciência, matériaprima dessa ficção, a narradora Dalloway utilizou uma linguagem fluida e transparente, como o elemento líquido, com as metáforas superpostas, transbordando umas das outras.

De fato, Solange de Oliveira, ao abordar a obra woolfiana, sublinhou com propriedade as relações entre arte e conhecimento:

As contínuas oscilações na vida interior das personagens, a miríade de emoções mútuas, não raro contraditórias, as frequentes mudanças de ponto de vista, as contínuas evocações do passado, lembram outros aspectos do Impressionismo; a pulverização do mundo pelo olhar, os inesperados ângulos de observação, e as diferentes visões de um mesmo objeto conforme as variações da luz. Características todas das notações ópticas de um Monet, esses rasgos estilísticos marcam a passagem do Impressionismo para um Simbolismo poético, no esforço de, como Mallarmé, tentar representar, non la chose, mais l'effet qu'elle produit (OLIVEIRA, 1990, p. 40) ${ }^{3}$.

Daí que, tem-se dado relevância ao fato de a obra de Virginia Woolf evoluir-se em círculo com vistas a conciliar "arte e moral", e ainda a relação entre "tradição e verdade", como anotara em seu diário, enquanto escrevia Mrs. Dalloway, em junho de 1923: "insubstancializo em certa medida, porque não tenho confiança na realidade - na sua mediocridade" (VALE, [s.d.], p. 98-99). Há que se observar a associação entre literatura e moral na própria origem do desenvolvimento dos estudos literários, ainda que consideremos a face superficial de moral, "relacionada a mores (costumes, hábitos)" - como chama a atenção José Luís Jobim, ao discutir o assunto em ensaio ilustrativo que evoca Madame de Staël, nome emblemático por sua atuação e embate nos estudos de literatura e cultura em âmbito mundial, especialmente o seu livro De la littérature, quando afirmava nos primórdios do século XIX:

A literatura só retira suas belezas duráveis da moral mais delicada. Os homens podem abandonar suas ações ao vício, mas jamais seu julgamento. Não é possível a nenhum poeta, qualquer que seja o seu talento, retirar um efeito trágico de uma situação que admitiria em princípio uma imoralidade [...] A crítica literária é com frequiência um trabalho de moral (STAËL apud JOBIM, 2002, p. 175).

Ainda segundo Jobim, as ideias de Madame de Staël teriam influenciado o nosso

\footnotetext{
${ }^{3}$ Solange Oliveira continuará dialogando com a análise de Jean O. Love, também especialista na obra woolfiana, e destaca importante trecho desse crítico: "a literatura é conhecimento sobre mundos apreendidos pela consciência... mas um tipo especial de conhecimento. É um conhecimento expresso em símbolos e, porque o processo da expressão da mudança, do desenvolvimento, o conhecimento simbólico diverge do conhecimento em si, anterior à expressão. Por essa razão, a literatura como conhecimento parcialmente expressa e parcialmente elabora, e portanto determina, o que sabe o autor" (LOVE apud OLIVEIRA, 1990, p. 52).
} 
Machado de Assis, que assim registrou leitura de obra da ilustre senhora: "uma obra é moral lembra-me ter lido em Mme. de Staël - se a impressão que se recebe é favorável ao aperfeiçoamento da alma humana... A moralidade de uma obra consiste nos sentimentos que ela inspira" (ASSIS apud JOBIM, 2002, p. 175-176). Também, das discussões de Jobim, interessanos repercutir que o ensaio citado, "a literatura como fonte da moral", buscou sua própria "fonte" em um lugar privilegiado e elevadamente significativo para nós: o levantamento original do acervo de Machado de Assis, no qual encontraram-se De la littérature considérée dans ses rapports avec les instituitions sociales, entre outras obras de Madame de Staël. Ora, sobre a repercussão mais que emblemática que envolve o nome da imortal senhora de Staël, não se pode esquecer particularmente sua movimentação intelectual em prol da cristalização dos estudos literários modernos, em especial das reflexões pioneiras em torno da prática comparatista relacionando literatura e cultura, em seguida amplamente difundida no mundo ocidental com o nome de literatura comparada. Isso nos leva a recuperar alguns pontos dessa história, pois que, ao mencionar a literatura comparada como método de trabalho e prática de conhecimento, seremos levados a tratar da redefinição valorativa do conhecimento, dentro de uma perspectiva valorativa de "ontem" e "hoje" da literatura comparada.

Madame de Staël representa a ativista mais genuína para a cristalização da expressão "literatura comparada". Assim juntos, seu nome e o desta "disciplina", hoje em declínio enquanto rótulo, provêm de campos de guerra e de embates de pensamento bem concretos: primeiro, que a obra De l'Allemagne, de Stäel, fora publicada em 1810, em Paris, e em seguida retirada de circulação e destruída sob ordens da polícia, constando que somente três anos mais tarde, em 1813, sairia oficialmente publicada em Londres, longe do alcance de Napoleão que, a partir de Paris, impunha sua guerra dentro de uma Europa retalhada em conflitos etnorraciais, em um clima de franca reação, intolerância e deliberada ignorância das outras literaturas e culturas. Nesse clima, o livro citado, também conhecido como "manifesto romântico", acompanhou a sorte desditosa de sua autora, posta na condição de mulher-viajante e intelectual errante, que transladou a literatura e a cultura de um país a outro, de uma cultura à outra, e nisso reside o segundo aspecto, ao favorecer a circulação das ideias, tornando o romantismo conhecido na França e também entre os italianos, Staël foi uma das mais exuberantes e animadas mulheres de seu século, a mulher mais extraordinária da época segundo Saint-Simon - aliás, ele também extraordinário, que, por isso, a pediu em casamento alegando que "deviam colaborar para produzir um filho mais extraordinário ainda" - como relata Edmund Wilson em Rumo à estação Finlândia, célebre livro sobre escritores e atores da história (WILSON, 1987, p. $81)$.

Com efeito, cabe ressaltar que Madame de Staël (Anne-Louise-Germaine, Madame Baronesa de Staël-Holstein) foi das mais formidáveis mulheres da história, personalidade brilhante, escritora, poeta, ativista política e feminista, além de tudo reconhecida como primeira filósofa política, talvez mais por reconhecer, já em sua época, a relatividade da noção de "belo" e de que em literatura tudo está se autofazendo, em uma autofagia constante, ao final alertando para o fato de que (em literatura) ser o dono da verdade é um aspecto extremamente pobre da consciência humana. Enfim, olhando a partir de hoje, sua gloriosa trajetória não só chama nossa atenção em época de globalização da cultura, como, também, recoloca no chão da contemporaneidade o pensamento de personalidades como Goethe, Voltaire, Rousseau e Diderot, que se reuniram em torno dela, empenhados em confrontações incessantes ${ }^{4}$. Ligado ao nome de Madame de Staël está um ilustrativo e histórico episódio, que, se não remonta ao enciclopedismo como derivação de "enciclopédia", ou de saber eciclopédico, certamente evoca o papel germinativo da leitura na imensa "comédia humana" de Balzac. Aliás, este episódio esteve interagindo até o momento enquanto leio a página de Balzac aberta sobre a mesa. Dele

\footnotetext{
${ }^{4}$ Remetemos para o excelente ensaio da professora Neide de Faria, que contextualiza a origem e o desenvolvimento dos estudos comparados, retraçando os aspectos históricos, teóricos e críticos da literatura comparada, desde os seus primórdios, com especial destaque à contribuição de Madame de Staël (FARIA, 1988).
} 
extraio a imagem da "leitura" e do encontro entre uma velha senhora e um jovem adolescente, que conversam em um tom de interrogação, especulação, como se propondo de modo especular uma forma de conhecimento: Madame de Staël encontrara-se, em um bosque, com Luís Lambert (que fora matriculado e mantido no colégio Vendôme pela própria Madame de Staël, e cuja imortalidade tinha sido preconizada por ela), e, vendo que o rapaz lia um livro, perguntalhe se "compreendia" o que lia, e o jovem Lambert responde perguntando à Ilustre Senhora se ela rezava a Deus; à afirmativa de Madame de Staël, Luís Lambert pergunta-lhe novamente - "e compreende-o?" (BALZAC, 1978, p. 219-221). Com esta delicada ironia e episódica picardia em torno da venerável senhora, que decisivamente impulsionou a literatura comparada rumo à cristalização de sua prática e abrangência mundiais, torna-se oportuno lembrar que, sem ela, Mme. de Stäel, pelo menos uma parte do pensamento europeu teria tomado direção diversa.

\section{REDEFININDO O CONHECIMENTO}

Ainda é Honoré de Balzac o nome evocado por Alejo Carpentier, em célebre conferência proferida em 1967, ao remarcar o amplo painel sociocultural, científico e tecnológico de nosso tempo e o descompasso do intelectual (romancista) em relação às transformações e evolução do conhecimento na contemporaneidade: "este não era o mundo de Balzac; este não era o mundo de Zola; este não era o mundo de Proust, nem ainda o de Joyce. Eles eram senhores dos seus mundos. Nós, os romancistas de 1967, estamos atrasados em relação a um mundo que é na realidade o mundo atual" (CARPENTIER, [s.d.], p. 87). Ao retomarmos a perspectiva de Carpentier, em seu argumento de perplexidade e ao mesmo tempo sintetizador do mal-estar em relação ao papel social do sujeito/intelectual frente a um mundo que não domina, de grande estranhamento, impõe-se não só acompanhar a arguta análise do intelectual que marcou época como, também, recolocar a questão do conhecimento hoje em dia, procurando esboçar um cenário catalisador desse mal-estar e uma possível inserção ou prática do sujeito inquiridor nas relações de saber. Assim, ilustrativa e emblemática é a passagem de Carpentier, que já à época conclamava:

$\mathrm{O}$ romancista de nosso dias sente-se, sob muitos aspectos, atrasado em relação à sua época, atrasado em relação a homens que não lhe desejam nenhum mal, que até leem os seus romances, mas que vivem em esferas que ele não atinge. Voa de avião sem saber porque deve apertar o cinto. Roça pelo mundo extraordinário da aviação comercial sem chegar a conhecer os seus mecanismos. Assiste à partida dos cosmonautas; vê as fotografias que eles trazem das suas viagens; volta-se para o mundo da medicina, e encontra-se em face de uma linguagem fechada; volta-se para os investigadores científicos, e encontra-se perante memórias, monografias, informações, de que não compreende absolutamente nada (CARPENTIER, [s.d], p. 86).

Acreditamos que a prática da literatura comparada como se delineia, ainda hoje, poderá acenar rumo a uma possível atuação/atitude tanto no ensino como na pesquisa e, enfim, na formatação do conhecimento como tal e rede de concatenação de saberes, provocativa do exercício da transdisciplinaridade. Dentre os vários aspectos que envolvem a posição do conhecimento na atualidade, decerto que, da nossa perspectiva seja como comparatista, historiador da literatura, ou como crítico literário e cultural, é possível reconhecer que o contexto histórico-sociológico foi corrosivo ao deslocar as premissas do pensamento, em um afastamento crucial - passagem da modernidade para a pós-modernidade, reverificação da própria modernidade lato sensu - do que reconhecemos como sendo o estádio contemporâneo das ciências humanas e o chão cultural que tudo envolve, não mais sob rótulos consagrados, mas antes sob o de "pós-tudo", incluisve do famoso poema concreto de Augusto de Campo, de 
1984. Se inumeráveis têm sido os actantes transformadores da Weltliteratur, como demonstra Wladimir Krysinski, em obra recente, destacam-se principalmente as tendências revolucionárias tanto no mundo como nas ideias que acabaram por recontextualizar as práticas de conhecimento, abrindo-se para um dos horizontes históricos mais fertilizadores do estudos comparativos. De uma perspectiva pioneira, René Wellek inicia a escrita de ensaio antológico sublinhando que nossas práticas de conhecimento, salientando inclusive a vida institucional, resultavam à deriva como se em sintonia com as turbulências do mundo pós-guerra: "o mundo (ou melhor, nosso mundo) encontra-se em estado de crise permanente, pelo menos desde 1914. Os estudos literários, em suas formas menos violentas e silenciosas, também estão divididos por conflitos metodológicos desde essa mesma época" (WELLEK, 1994, p. 108). A partir daí, quer venha de escritores e/ou intelectuais, quer de filósofos, e sobremodo especial dos movimentos sociais e das revoltas modernistas, a constatação é a de que as relações humanas, a explicação cartesiana do mundo, a compreensão euclidiana da realidade perderam ou mudaram de solo. Virginia Woolf, por exemplo, chamará a atenção em um de seus inúmeros e notáveis ensaios, ao enfatizar que: "em ou por volta de dezembro de 1910, a natureza humana mudou [...]. Todas as relações humanas mudaram - entre patrões e empregados, maridos e mulheres, pais e filhos. E, quando as relações humanas mudam, há ao mesmo tempo uma mudança na religião, no comportamento, na política e na literatura" (WOOLF, 1988, p. 420). Recentemente, Krysinski enfatiza o estado de revolvimento planetário no pós-guerra, e não só constata que uma época passou, mas, também as certezas epistemológicas flectiram-se consideravelmente, resultando em uma inapreensibilidade do todo, que a antiga Weltliliteratur não mais se reconhece no seu surgimento com Goethe e observa enfim:

Deve-se admitir que, grosso modo, desde o fim da Segunda Guerra Mundial, desde o momento em que se instalou a tão profunda crise do Estado-Nação e do Estado-Federação, desde o advento do nomadismo moderno que se constituiu em fenômeno planetário e em resultado do empobrecimento vertiginoso de uns e do enriquecimento de outros, resultado das múltiplas guerras locais e não tão locais, dos golpes militares e das ditaduras, deve-se admitir que o local e o marginal forçam o nacional, o institucional e, portanto, o universal a agir. Com isso o universal tem dificuldades para reencontrar-se em uma unicidade de estruturas temáticas ou formais que pareciam evidentes para Goethe, mas que são indecidíveis hoje (KRYSINSKI, 2007, p. 8).

Como se vê, um sentido trágico está a envolver a situação da literatura e conhecimento no cenário atual. O desafio da contemporaneidade é continuar repetindo e repondo questões candentes como se a leitura literária ainda significasse não apenas abertura ao mundo, aos livros, mas à biblioteca infinita que constitui, hoje, o patrimônio cultural como um todo. Assim expandida, a condição da contemporaneidade torna-se gesto radical a envolver, inclusive, a noção de hipertexto, quando textos de caráter mutante se encontram com leitores que esboçam caminhos possíveis e acidentais. Assim como observou o crítico em "Identidades atravessadas":

Nesta situação, de certo modo incomensurável, reaparece de forma nova a figura do paradoxo. E esse é um lembrete para a teoria da literatura que precisa aprender o seu sentido alterado, não para salvaguardar, mais uma vez, um lugar singular na esfera cacofônica da cultura de contextualização veloz, mas para, de algum modo, colocar à prova e legitimar a sua própria importância e sobrevivência (OLINTO, 2001, p. 111-112).

De fato, trata-se hoje de recolocar o conhecimento segundo uma grade rarefeita, ao mesmo tempo refratária ao modelo de pensamento bem trançado nas lançadeiras dos silogismos 
e/ou saberes adrede explicados, expressivamente assentado em um realismo/naturalismo pretendente à dominação e controle de causa e efeito. Nesse sentido, Pierre Lévy observou que a própria língua é uma "trama infinitamente complicada onde se propagam, se dividem e se perdem as fulgurações luminosas do sentido. As palavras já são interfaces, colocadas em ressonância por uma voz, distendidas ou torcidas por um canto, estranhamente conectadas a outras palavras por um ritmo ou rimas, projetadas no espaço visual pela escrita, padronizadas, multiplicadas e colocadas em rede pelo impresso, mobilizadas" (LÉVY apud SANTOS, 2001, p. 7), fertilizando assim o conhecimento, a propagação de atividades nas redes transitórias, abertas, que se bifurcam - como em "O jardim de caminhos que se bifurcam", conto antológico de Borges.

Interfaces, transições: faces sígnicas do conhecimento. Ou, como nos ensinam as epistemologias do nosso tempo, todo conhecimento passa a residir na articulação dos suportes, no agenciamento das interfaces; se os mais diversos agenciamentos compósitos podem interfacear - tradução, transformação, passagem, o que é da ordem da interface - é porque todo conhecimento reside na articulação dos suportes, na arquitetura da rede. Com efeito, está-se no campo de uma operação cognitiva, que ilustramos com o comparatismo em suas multifaces, onde a capacidade de "relacionar" compartilha com a de "articulação", talvez o ponto cego de um trompe-l'oeil raramente perspectivado, no qual o conhecimento resultaria da capacidade de articulação dos saberes e de igual competência para proporcionar o diálogo "entre os métodos de abordagem segundo a natureza da questão levantada pelo investigador" (MACHADO e PAGEAUX, 1988, p. 17). Assim, todas as formas e práticas possíveis do que chamamos literatura comparada e produção do conhecimento decorreriam de um indecidível que constitui a seleção e o olhar de cada investigador/observador, segundo a ardilosa arquitetura com que cada um entra e sai de Babel. Se retomarmos a clássica conceituação que começava por ensinar que "a literatura comparada é arte metódica" (BRUNEL, 1995, p. 139), hoje essa analogia só pode ser produtiva em sentidos quando "a 'arte', como toda a 'Arte', é a do trompe-l'oeil...":

- A pintura é uma gaia-ciência, uma máquina de produzir anjos e quimeras, objectos que são e não são objectos; é uma máquina carnal cujo mistério reside na pele, à flor da pele, e cuja profundeza reside na superfície. A pintura baralha todas as categorias, pintura que pensa de um modo necessariamente possessivo e reflecte o próprio gesto de pensar e representar. Pintura e dinâmica de forças e secretas pressões que a consciência não alcança. Um castelo da alma que produz visões, cartas e epifanias, falsos espelhos e enigmas ${ }^{5}$.

Noção essa, do trompe-l'oiel, que vem da filosofia contemporânea, em ensaio intitulado "Zeuxis e Babel - Imagens de Filosofia", cujo autor inicia dedicando-o a George Steiner, significativo paratexto dessas reflexões ${ }^{6}$. Ao reunir Babel e trompe-l'oeil, duas imagens portentosas de "confusão", o filósofo põe em cenário a potência da "articulação", como própria do conhecimento, sem esquecer que Babel é o observatório que tenta unir os mundos subterrâneo e cavernoso, a terra e os céus. A palavra "Babel", diz o filósofo, em hebraico, quer dizer Porta de Deus (Bab-Ilu: Bab = Porta, e El = Deus), Porta do Céu, e bâlal aponta para "confundir", "baralhar", "embrulhar":

Em suma, a marca da contemporaneidade, se é que existe

\footnotetext{
${ }^{5}$ A citação foi extraída do ensaio "Zeuxis e Babel - Imagens de Filosofia", cujas linhas/entrelinhas desconstroem e ressignificam a aventura viva da contemporaneidade. Consultar: COSTA, Carlos Couto Siqueira. p. 461. Disponível em: http://ler.letras.up.pt/uploads/ficheiros/1930.pdf. Acesso em: 11 de junho de 2011.

${ }^{6}$ Referimo-nos ao famoso ensaio "O que é literatura comparada?", de George Steiner, proferido como Aula Inaugural na Oxford University, em 1994 (STEINER, 2001, p. 159).
} 
contemporaneidade(s), reside então nessa explicação-complicação de cruzamentos e escritos [...] E isto porque a maravilha das maravilhas já não é que o Ser seja, mas sim que as metáforas, os transportes e as diferenças, persistam e se reflictam infinitamente, como em um caleidoscópio ou no modelo reticular de Penélope, infatigavelmente urdindo e desurdindo a sua teia, até a exaustão. Contemporaneidade que nos assiste também na distribuição, circulação, tradução e na criação do que alguns chamaram provocatoriamente de artrologia não astrologia, mas que sei eu disso - ou aquela ciência dos articuli, das articulações entre dispositivos de saber, de poder saber (STEINER, 2001, p. 159).

$\mathrm{O}$ aspecto do mal-estar na civilização tem sido retomado constantemente. Ítalo Calvino, em Seis propostas para o próximo milênio, adverte que, em um momento em que a ciência desconfia das explicações gerais e das soluções que não sejam setoriais e especialísticas, o grande desafio para a reflexão filosófica é o de saber tecer em conjunto os diversos saberes e os diversos códigos, em uma visão pluralística e multifacetada do mundo, ou seja, o conhecimento como rede de concatenações. Sobre isso é preciso ainda uma pergunta e duas palavras: como realizar a combinação, hoje, entre tecnologias da imagem e tecnologias da escrita, pensando na permanência do livro/ literatura, primado da escrita, como repositório de conhecimento? Sob o ponto de vista e o lugar em que me situo na cultura, o de um pesquisador e docente da área de ciências humanas, mais especificamente das Letras, devo dizer que meu olhar parte de um determinado campo de experiência e do conhecimento que não elimina outros prismas, embora privilegie determinados argumentos. Segundo Carvalhal (2005), se considerarmos a ideia de que hoje dispomos de duas livrarias ou bibliotecas, sendo uma virtual e outra material, dispostas nas estantes das livrarias, devemos lembrar que os livros e esses espaços não deixam de existir com as inovações tecnológicas, antes com elas convivem e de certa forma se complementam. Por isso não interessa a pergunta se o livro vai acabar, mas sim indagar sobre as modificações introduzidas na relação do leitor com o livro pelas novas tecnologias, sobre a mudança de seu estatuto e modos de atuação. Uma das características essenciais de nosso tempo, que estaria na construção do pensamento científico, diz respeito à inter-relação dos saberes, noção que está na base do pensamento e das práticas interdisciplinares. Por outro lado, outra característica de nosso tempo associa-se a anterior, ou seja, à universalização do saber, que se refere à disseminação e à apropriação do saber. A disponibilização dos livros em rede de internet, como o projeto realizado pela Biblioteque de France, do qual Roger Chartier é um de seus mentores, objetiva a disponibilidade universal do patrimônio escrito que se torna, assim, universal, em um certo sentido invalidando e tornando obsoleta a própria existência da Biblioteca Nacional. No entanto, todas as alterações, por mais fantásticas que sejam, têm seus riscos, pois, como afirmou o próprio Chartier, citado por Carvalhal $(2005$, p. 3), "a transferência do patrimônio escrito para a tela inaugura imensas possibilidades, mas será também uma violência contra os textos, separados da forma que contribuíram para construir as suas significações históricas". Assim, a lição de nosso tempo parece ser substancialmente esta: que a "universalização do saber", facilitada pela tecnologia, não provoque a "separação entre os saberes" mas, antes,

[...] estimule a interação entre linguagens, o interdiscursivo, o interdisciplinar. Essas exigências ou desafios encaminham para a necessidade de formulações de projetos pedagógicos que sustentem a aplicação das novas tecnologias. Que o fascínio exercido sobre nós por esses recursos, que aparentemente introduzem facilidades em nossas rotinas, não nos impeça de ver seus riscos nem de atentar para seus limites. Que o adestramento necessário para que pilotemos esse novo instrumental não nos disperse do essencial cultivo da arte de voar, nem que as experiências com o mundo "virtual" não nos 
distanciem do mundo real (CARVALHAL, 2005, p. 5).

Desse ângulo de observação, torna-se constante na ordem do dia a reposição de natureza especulativa, "interrogativa", como no título $O$ que é o contemporâneo?, de Giorgio Agamben", dentro de um contexto que pugna pela alteração de paradigmas, pelo deslocamento do conceito e prática das noções de conhecimento, ciência, teoria e compreensão articuladas no período moderno; pela "redefinição" de campos disciplinares enquanto legado do cogito moderno, que selecionava e hierarquizava o saber segundo uma grade de disciplinas; pela evocação enfim do conhecimento como prática transdisciplinar, de trans/versões (AGAMBEN, 2009; MIGNOLO, 2003; SOUZA, 2007; DOMINGUES, 2004) ${ }^{8}$. Neste sentido, em destacado grau de convergência surgem os esforços renovados de diversas áreas, campos de atuação ou núcleos de estudos, como é o caso do Instituto de Estudos Avançados Transdisciplinares (IEAT), criado em 1999 na Universidade Federal de Minas Gerais, cujos objetivos, plano de atividades e distinguidas publicações merecem ser destacados ${ }^{9}$. Em ensaio inaugural do IEAT, reveladoramente intitulado "Um novo olhar sobre o conhecimento", que também abre o livro de evocativo título, Conhecimento e transdisciplinaridade, Ivan Domingues chama a atenção, primeiro, para a real missão do Instituto, ao observar que:

Ao se propor a criação de um Instituto de Estudos Avançados Transdisciplinares (IEAT) no âmbito da UFMG, procura-se dar um passo a mais no processo de complexificação do conhecimento, bem como introduzir um elemento indutor da ação catalisadora (no caso, a ação do próprio Instituto e dos grupos a ele ligados), capaz de interferir na organização atual do saber e de corrigir seus próprios rumos, infletindo-os vigorosamente para o novo e o futuro (DOMINGUES, 2004, p. 17).

Igualmente instigante e ilustrativa das renovadas práticas de conhecimento é a explicação que o autor formula para a "passagem" da transdisciplinaridade:

\footnotetext{
${ }^{7}$ Neste livro, de recente especulação sobre o contemporâneo, Agamben pontua uma adjetivação para o termo, e ressignifica-o na imagem "das vértebras quebradas do século" (AGAMBEN, 2009, p. 61), e que "o presente que a contemporaneidade percebe tem as vértebras quebradas. O nosso tempo, o presente, não é, de fato, apenas o mais distante: não pode em nenhum caso nos alcançar. O seu dorso está fraturado, e nós nos mantemos exatamente no ponto da fratura" (AGAMBEN, 2009, p. 65).

${ }^{8}$ Neste aspecto, convergem palavras de Rildo Cosson ao enfatizar "o futuro das Letras": "os estudos literários têm passado por profundas transformações nos últimos anos. Questões como abertura do cânone, quebra das oposições entre alto e baixo, popular e erudito, ampliação do corpus literário para além das coordenadas estéticas, apagamento de fronteiras da literatura em relação a disciplinas como a história, a sociologia e a antropologia, entre tantas outras, têm colocado em discussão as noções tradicionais de exegese, interpretação e avaliação do texto literário. Os novos aportes teóricos e metodológicos - a exemplo do pós-estruturalismo, desconstrução, crítica feminista, psicoanálise, novo historicismo, teoria do discurso, pós-colonialismo, etc. - não apenas renovam os conhecimentos da área, como também desafiam a própria maneira pela qual ela é constituída” (COSSON, 2000, p. 7).

${ }^{9}$ É relevante sublinhar a vocação do IEAT voltado para "o modelo atual da "universidade transnacional empresarial' [que] não mais consegue dar respostas que produzam avanços significativos nas grandes questões sociais e humanas, apesar do fabuloso avanço científico e tecnológico que ela produziu, principalmente depois da Segunda Guerra Mundial, e que continua a produzir numa velocidade cada vez maior. A razão pela qual a instituição universitária atual não consegue produzir mudanças conceituais profundas é que ela tem justificado sua existência em uma auto-reflexão fundada em valores econômicos, estabelecidos pela cultura dos bens de consumo de base industrial e de base tecnológica, motivo pelo qual ela se burocratizou". Além do volume referido, Conhecimento e transdisciplinaridade, o IEAT da UFMG mantém a publicação dos "Cadernos" e mostra-se em consonância com outros Centros e Institutos no Brasil e no mundo (BARRETO, 2004, p. 31-32).
} 
Por transdisciplinaridade, que vem a ser o verdadeiro eixo do IEAT, entende-se antes de mais nada, ao se pôr em relevo o prefixo trans(que, além da acepção de "através" ou de "passar por", encerra os sentidos de "para além", "passagem", "transição", "mudança", transformação" etc.), aquelas situações do conhecimento que conduzem a transmutação ou ao traspassamento das disciplinas, à custa de suas aproximações e freqüentações. Pois, além de sugerir a ideia de movimento, a transdisciplinaridade permite pensar o cruzamento de especialidades, o trabalho nas interfaces, a superação das fronteiras, a migração de um conceito de um campo de saber para outro, além da própria unificação do conhecimento (DOMINGUES, 2004, p. 17-18).

Essa mesma ideia, como matriz do Instituto e fórmula para a explicação da transdisciplinaridade, é retomada noutro ensaio do mesmo livro, "Um novo olhar sobre o conhecimento", no qual seu autor lembra que

[...] o prefixo trans-, além da acepção de "através", evoca os sentidos de "para além", de "passagem", de "transição", e remete a processos de conhecimento que concebem a fronteira como espaço de troca e não como barreira, processos que incitam à migração de conceitos, à frequentação exploratória de outros territórios, ao dialogo modificador com o diverso e o de outra forma, processos que não se esgotam na partição de um mesmo objeto entre disciplinas diferentes, prisioneiras de pontos de vista singulares, irredutíveis, estanques, incomunicados (SILVA, 2004, p. 36-37).

Também Tania Carvalhal (2002), em profícuo colóquio dedicado às "trans/versões" comparatistas, registrava, com palavras a serem destacadas, outros revolvimentos e movimentação no mundo e nas ideias, ao tomar como ponto de referência o ano de 1971:

Outubro de 1971. Um vento de liberdade sopra no outono parisiense. A grande revolução de três anos atrás modificara o perfil da universidade francesa, alterando também algumas estruturas sociais. A universidade de Paris VIII, Vincennes, ainda guardava as marcas desta revolução em desenhos e grafites, expressão de um novo estatuto, fruto da rebeldia, que se manifestava também no vestuário e nos cabelos longos dos estudantes. Nanterre, Paris X, recém-criada, era igualmente um núcleo de renovação nas relações acadêmicas e institucionais. Importa sobretudo sublinhar que essa não era uma alteração de superfície mas correspondia a um desdobramento intelectual que se processava igualmente na variedade de orientações teórico-críticas com que um estudioso de literatura se deparava (CARVALHAL, 2001, p. 147).

Assim, em uníssono a voz da ensaísta, lembremos que, se em todo movimento literário há um aspecto de revolta e tradição, também o campo da reflexão e análise do conhecimento responde com um paradigma, ao qual a capacidade de reformular nosso desejo de investigação abre-se como possível resposta às nossas indagações. De fato, lembra a ensaísta, na trajetória de um escritor como Roland Barthes constatam-se perspectivas diversas, de acordo com o percurso da pesquisa que vai se atualizando em função do renovado olhar do pesquisador em relação com o contexto sociocultural. Ao refazer o percurso da obra bartheseana, por exemplo, Tania Carvalhal mostra como tal percurso está ligado à noção de seuil, de trânsito e 
principalmente à ideia de transgressão e de ultrapassagem - paradigma que nos acompanhou até aqui. Com esse élan para a pesquisa, reconhece-se na trajetória do escritor que, sem ser um comparatista de oficio, ele o foi avant la lettre, na medida em que contribuiu para a alteração de paradigmas. Sua atividade crítica corroboraria com a da pesquisa, fazendo com que a "articulação" do campo literário com outras disciplinas, perspectivando o prefixo trans-, contribuísse para o avanço da prática de outro prefixo, o de pós-, hoje de larga escala: pósdisciplinares, pós-estruturalistas, pós-coloniais, etc ${ }^{10}$. Assumindo a perspectiva sugerida pela ensaísta, sublinha-se que o mais importante no conjunto da obra bartheseana é a insistência com que o crítico ensaia soluções para seu próprio métier: "o trabalho do crítico não é descobrir o significado secreto de uma obra - uma verdade do passado - mas constituir o inteligível do nosso tempo", ou ainda, "o que sempre me fascinou na vida é o modo como as pessoas tornam seu mundo inteligível". (BARTHES apud CARVALHAL, 2002, p. 150). Para este rumo sinalizaria o trabalho da pesquisa como resultado da nossa capacidade de articular, de relacionar a nossa própria produção de conhecimento, enquanto marca da contemporaneidade, com as multifaces de saberes do presente. Assim, articulando a sugestão de nossos dois ensaístas, caberia ao comparatista "tornar o nosso mundo legível", como queria Barthes, no mesmo compasso que o posiciona "sob a égide do cavaleiro errante", segundo Tania Carvalhal: "em suas múltiplas variações, a literatura comparada vive a aventura dos tempos e enfrenta, na formulação de perguntas, sua permanente validação" (CARVALHAL, 2006, p. 17).

À guisa de conclusão, são oportunas as enfáticas palavras do comparatista Daniel-Henri Pageaux (2011) ao postular "por um novo humanismo", o qual que não se confundiria com a ideia de herança, de patrimônio, ou, ainda, com a mistura de saber e ética que servira para defender e ilustrar "com força e nobreza, uma certa ideia do homem"; nem se confundiria com a erudição ou o ideal enciclopédico ou de cultura geral que formataram nossa história das ideias: "o humanismo comparatista no qual estou pensando tem o dever de considerar o homem como tema de reflexão e análise" (PAGEAUX, 2011, p. 253). E especialmente na bela e provocativa passagem da síntese que propõe:

Diante da proliferação das informações e da fragmentação das questões e dos saberes, o comparatismo pode assumir a função difícil, mas exaltante, de disciplina de síntese, não com o fim de alinhar belas conclusões gerais, mas para criar meios de se pensar um pouco acerca da totalidade na qual estamos imersos (PAGEAUX, 2011, p. 255 - grifos meus).

$\mathrm{E}$, assim, da lição do mestre, sendo verdade que não nascemos comparatistas mas nos tornamos comparatistas, e que é preciso poder, ou querer, continuar sendo comparatista depois de sê-lo, aprenderemos que:

[...] o novo humanismo, o comparatismo renovado devem dar novamente a palavra aos criadores, além de tentar conciliar reflexão e criação, abordagem teórica e perspectiva poética, já que certas práticas universitárias as dissociaram (PAGEAUX, 2011, p. 263).

\footnotetext{
${ }^{10}$ Neste sentido, como sublinha Carvalhal, a alteração de paradigmas reflete-se nas propostas e títulos de trabalhos que já modificaram, à época, tanto o perfil da universidade como algumas estruturas sociais, cuja orientação não era só de superfície, mas correspondia à variedade de orientações teórico-críticas com que um estudioso da literatura se deparava: Douwe Fokkema publica "A literatura comparada e o novo paradigma”, Eva Kushner publica "Em direção de uma tipologia dos estudos de literatura comparada", e Gerald Gillespie publica "Rinoceronte, unicórnio ou quimera? Visão polissistêmica de uma possível tipologia da literatura comparada no próximo século” (CARVALHAL, 2002, p. 149).
} 


\section{BIBLIOGRAFIA}

AGAMBEN, Giorgio. O que é o contemporâneo? Chapecó: Argos, 2009.

BALZAC, Honoré de. A comédia humana. 15º vol. Porto: Livraria Civilização Editora, 1978.

BARRETO, Francisco César de Sá. A instabilidade como condição para mudanças institucionais qualitativas. In: DOMINGUES, Ivan (organização). Conhecimento $e$ transdisciplinaridade. Belo Horizonte: UFMG; IEAT, 2004. p. 29-33.

BLOOM, Harold. Orlando de Virginia Woolf: feminismo como amor à leitura. In: $O$ cânone ocidental. Trad. Marcos Santarrita. Rio de Janeiro: Objetiva, 1994. p. 414-426.

BRUNEL, P.; PICHOIS, C.; ROUSSEAU, A. M. Que é literatura comparada? São Paulo: Perspectiva, 1995. p. 139-144.

CARPENTIER, Alejo. Literatura e consciência política na América Latina. Trad. Manuel Palmeirim. São Paulo: Global, [s.d.].

CARVALHAL, Tania Franco. Limiares, passagens e paradigmas: o curso da pesquisa. In: BITTENCOURT, Gilda Neves da Silva (organização). Trans/versões comparatistas: I Colóquio Sul de Literatura Comparada e Encontro do GT de Literatura Comparada da ANPOLL. Anais... Porto Alegre: UFRGS - Instituto de Letras; PPG-Letras, 2002. p. 147-150.

Sob a égide do cavaleiro errante. Revista Brasileira de Literatura Comparada. Rio de Janeiro, n. 8, jul. p. 11-17, jul. 2006.

Futuro da docência na universidade: tecnologias da imagem ou tecnologias da escrita? Porto Alegre, 2005. 10 f. Mimeografado.

COSSON, Rildo. 2000 palavras: o futuro das letras. In: __. (Organização). O presente e $o$ futuro das Letras. Pelotas: Programa de Pós-Graduação em Letras - UFPel, 2000.

CURY, Maria Zilda Ferreira. Intelectuais em cena. In: CURY, Maria Zilda; WALTY, Ivete (organização). Intelectuais e vida pública: migrações e mediações. Belo Horizonte: UFMG, 2008. p. 11-28.

DOMINGUES, Ivan (organização). Conhecimento e transdisciplinaridade. Belo Horizonte: UFMG; IEAT/UFMG, 2004.

DOMINGUES, Ivan et alli. Um novo olhar sobre o conhecimento: a criação do Instituto de Estudos Avançados da UFMG, as pesquisas transdisciplinares e os novos paradigmas. In: DOMINGUES, Ivan (organização). Conhecimento e transdisciplinaridade. Belo Horizonte: UFMG; IEAT, 2004. p. 13-27.

FARIA, Neide de. Literatura comparada: ontem e hoje. Revista de Extensão. Campo Grande (MS), v. 1, n. 1, p. 14-20, 1988.

JOBIM, José Luís. A literatura como fonte da moral. In. _. Formas da teoria: sentidos, conceitos, políticas e campos de força nos estudos literários. Rio de Janeiro: Caetés, 2002. p. 173-188.

KRYSINSKI, Wladimir. Narrativa de valores: os novos actantes da Weltliteratur. In:

Dialéticas da transgressão: o novo e o moderno na literatura do século XX. São Paulo: Perspectiva, 2007. p. 1-14.

LHERMITTE, François. O pensamento sem linguagem. Trad. Itamar Sant'Anna Verburg. Diógenes. Brasília, n. 9, p. 91-102, 1985.

MARQUES, Reinaldo. Literatura comparada e estudos culturais: diálogos interdisciplinares. In: CARVALHAL, Tania Franco (organização). Culturas, contextos e discursos: limiares críticos no comparatismo. Porto Alegre: Editora da Universidade (UFRGS), 1999. p. 58-67.

MACHADO, Antonio M.; PAGEAUX, Daniel-Henri. Da literatura comparada à teoria da literatura. Lisboa: Edições 70, 1988.

MIGNOLO, Walter. Histórias locais / projetos globais: colonialidade, saberes subalternos e pensamento liminar. Belo Horizonte: UFMG, 2003.

OLIVEIRA, Solange Ribeiro de. A arte como conhecimento: To the lighthouse, de Virginia Woolf. Revista Ilha do Desterro. Florianópolis, n. 24, 1990, p. 39-63. 
OLINTO, Heidrun K. Identidades atravessadas: teoria de literatura e seus objetos oscilantes. In: COUTINHO, Eduardo (organização). Fronteiras imaginadas: cultura nacional / teoria internacional. Rio de Janeiro: Aeroplano, 2001. p. 105-118.

PAGEAUX, Daniel-Henri. Comparatismo e humanismo: espaços para reflexão. In: __. Musas na encruzilhada: ensaios de literatura comparada. Organização de Marcelo Marinho, Denise Almeida Silva e Rosani Umbach). Santa Maria: UFSM; URI; HUCITEC, 2011. p. 249-263.

PAZ, Octavio. O mono gramático. Rio de Janeiro: Guanabara, 1988.

SANTOS, Paulo Sérgio Nolasco dos. Nas malhas da rede: uma leitura crítico-comparativa de Julio Cortázar e Virginia Woolf. Campo Grande: UFMS, 1998.

Apresentação. In: __. (Organização). Literatura comparada: interfaces e transições. Campo Grande (MS): UFMS, 2001. p. 5-8.

SILVA, Evando Mirra de Paula e. Os caminhos da transdisciplinaridade. In: DOMINGUES, Ivan (organização). Conhecimento e transdisciplinaridade. Belo Horizonte: UFMG; IEAT, 2004. p. 35-43.

SOUZA, Eneida Maria de. Tempo de pós-crítica. São Paulo: Linear B; Belo Horizonte: Veredas \& Cenários, 2007.

STEINER, George. O que é literatura comparada? In: __. Nenhuma paixão desperdiçada. Rio de Janeiro: Rocco, 2001. p. 159-166.

SZABOLCSI, Miklós. Literatura universal do século XX: principais correntes. Trad. Aleksandar Javanović. Brasília: UnB, 1990.

VALE, Francisco. Virginia Woolf: viajante solitária de regiões desconhecidas (posfácio). In: WOOLF, V. A casa assombrada. Trad. Miguel Serras Pereira. Lisboa: Relógio d’Água, [s.d.], p. 93-100.

WELLEK, René. A crise da literatura comparada. Trad. Maria Lúcia Rocha-Coutinho. In: COUTINHO, Eduardo e CARVALHAL, Tania Franco (organização). Literatura comparada: textos fundadores. Rio de Janeiro: Rocco, 1994. p. 108-119.

WILSON, Edmund. Rumo à estação Finlândia: escritores e atores da história. Trad. Paulo Henriques Britto. São Paulo: Companhia das Letras, 1987.

WOOLF, Virginia. "Mrs. Dalloway na Bond Street". In:__. Uma casa assombrada. Trad. José Antonio Arantes. Rio de Janeiro: Nova Fronteira, 1984. p. 181-193.

Mrs Dalloway. Trad. Mário Quintana. Rio de Janeiro: Nova Fronteira, 1980.

Como se deve ler um livro? In: ___ O leitor comum. Trad. Luciana Viégas. Rio de Janeiro: Graphia, 2007. p. 123-135.

. The Essays 1916: Hours in a Library. In: __. The Essays of Virginia Woolf. Volume 2: 1912-1918. Edited by Andrew McNeillie. London: The Hogart Press, 1988. p. 55-61.

. Character in fiction. In: _. The Essays of Virginia Woolf. Volume 3: 1919-1924. Edited by Andrew McNeillie. London: The Hogart Press, 1988. p. 420-438. 